\title{
Resenha
}

Sombras autoritárias e totalitárias no Brasil: integralismo, fascismo e repressão política. João Fábio BERTONHA (Org.), Maringá: Eduem, 2013.

\section{Vinicius Ramos}

A organização do livro Sombras autoritárias e totalitárias no Brasil fica a cargo de João Fábio Bertonha, doutor em História pela Unicamp, professor do departamento de História da Universidade Estadual de Maringá. Prefaciado por René Gertz, o livro se insere no esforço dos pesquisadores associados ao "Grupo de Estudos sobre os movimentos autoritários do século XX", comandado pelo professor Bertonha, que se divide em duas linhas de pesquisa: 'Integralismo e pensamento autoritário brasileiro no século XX' e 'Movimentos políticos e imigração no século XX'.

A partir de três eixos temáticos se articula o livro. 'O Integralismo: novos estudos e abordagens', 'Os imigrantes do Eixo, os integralistas e a repressão aos dissidentes no estado do Paraná e ' Pensamento e práticas autoritárias no entre guerras e além'.

O primeiro artigo é assinado por dois pesquisadores, Luciana Agostinho Pereira e Rafael Athaides e se intitula 'A Ação Integralista em Mato Grosso (1933-1937)'. Neste trabalho é feito um estudo de caso sobre a atuação da Ação Integralista Brasileira (AIB) no estado do Mato Grosso. O estudo se inicia com uma breve contextualização sobre o integralismo e sua abrangência nacional, prosseguindo com um relato sobre a situação do Mato Grosso na década 1930, quando ainda não havia ocorrido a separação do grande estado em duas porções, buscando a trajetória das disputas políticas sobre o território e o processo de modernização de algumas cidades mato-grossenses, onde justamente o integralismo teve maior adesão. Os autores se utilizam da imprensa integralista como fonte primária do estudo, o que tornou possível apreender a dificuldade de administração da AIB no Mato Grosso por conta de sua grande extensão, razão pela qual a chefia nacional decide dividir a província - nome dado à divisão administrativa da Ação Integralista Brasileira - em três partes: a primeira com sede em Campo Grande, a segunda com sede em Corumbá e a terceira com sede em Cuiabá. Através do jornal integralista $A$ Offensiva, principal meio de comunicação da organização, os autores traçam um panorama da campanha eleitoral para presidência - no estado do Maranhão - que ocorreria em 1938, na qual Plínio Salgado saiu candidato. Através dos informes dos militantes mato-grossenses publicados no jornal, é possível reconstruir parte desta história. Por fim, o artigo traz um esquema sobre a origem social dos membros da AIB no Maranhão, que se cristaliza como um retrato fiel do caso nacional, com a classe média dominando as fileiras integralistas, sendo os militares de alta patente, junto com as classes médias altas, pertencendo geralmente à cúpula do partido, enquanto que os praças e a classe média baixa formavam o grosso da organização (Bertonha, 2013). 
No segundo artigo do livro, a imprensa novamente é a fonte principal do estudo. Através do jornal A Offensiva, Murilo Antonio Paschoaleto constrói sua argumentação para produzir ' $\mathrm{O}$ integralismo e o nazismo em perspectiva: uma análise da Alemanha nazista presente nas páginas do jornal integralista A Offensiva (1934-1938)'. Repetindo o trajeto do primeiro artigo, uma pequena reflexão sobre a AIB abre o estudo, que logo se desdobra na análise do maior jornal integralista, que circulava nas grandes capitais brasileiras. $\mathrm{O}$ autor busca refletir acerca das ponderações do periódico e sua relação com o nazismo e elege algumas de maior relevância, tais como a busca por diferenciar o fascismo do nazismo no que diz respeito à sua originalidade, buscando o jornal mostrar o integralismo como um movimento que se insere num contexto internacional propício, e não como um movimento mimético. Outro evento analisado pelo autor é o episódio da prisão e execução de muitas lideranças das tropas da $S A$ por Hitler acusadas de alta traição e tentativa de um golpe de Estado. A Offensiva trazia para si a responsabilidade de relatar os verdadeiros acontecimentos que a Alemanha testemunhou que segundo o jornal haviam sido deturpados pela imprensa nacional e internacional numa tentativa de desacreditar o regime nazista e Adolf Hitler. Por fim, o Caso Sarre - disputa territorial entre Alemanha e França - e a prisão de padres na Alemanha, foram alvos de atenção do periódico integralista e analisados pelo autor, sendo respectivamente a posição de $A$ Offensiva, de apoio e crítica à Alemanha. Ou seja, Paschoaleto identifica idas e vindas na relação do jornal integralista com a Alemanha nazista (Bertonha, 2013).

O terceiro artigo é de autoria de Jaqueline Tondato Sentinelo, 'A Nação Integral: uma proposta autoritária de nação para o Brasil na década de 1930’. A autora busca trazer um panorama sobre o projeto de nação que o integralismo propunha. Nesse percurso a autora retoma o contexto da virada do século XX e a posição da intelectualidade brasileira com respeito às teorias do branqueamento da população assim como a valorização da mestiçagem e a modificação da preponderância de uma para outra. Desta forma, a autora busca um diálogo entre esta valorização do mestiço, do caboclo, com o projeto nacionalista e autoritário da Ação Integralista Brasileira (Bertonha, 2013).

O quarto artigo do livro é de autoria de Leandro Luiz Cordeiro. 'Alceu Amoroso Lima e a intelectualidade católica frente ao integralismo’ faz um balanço do posicionamento dos intelectuais católicos na sua relação com a AIB, e foca sua observação no principal representante daquele grupo, Alceu Amoroso Lima, também conhecido pelo seu pseudônimo Tristão de Athayde. Cordeiro inicialmente traça um panorama geral da situação dos intelectuais católicos brasileiros no começo do século XX, para posteriormente observar as idas e vindas, afagos e acusações do catolicismo para com o integralismo, sendo considerado por muitos seguidores da Santa Sé, perigoso por se tratar quase de uma religião alternativa. Ou seja, da mesma forma que Amoroso Lima mostra simpatia com o integralismo, também identifica nele uma ameaça à hierarquia e à ordem católica (Bertonha, 2013).

O trabalho de número cinco fica por conta de Rafael Athaídes, 'Militância integralista em tempos de proscrição: Manoel Ribas e a precoce repressão à Ação Integralista Brasileira no Paraná (julho de 1935 - dezembro de 1936)'. O trabalho de Athaídes é focado no estado do Paraná e analisa as tensões entre a A.I.B. e o governador do estado, Manoel Ribas. $\mathrm{O}$ artigo se inicia com um breve relato sobre a atuação do integralismo naquele estado, sempre permeada por intrigas e convulsões devidos às 
atividades desenvolvidas pelos integralistas, que muitas vezes pareciam desafiadoras para a polícia. E esta relação conflituosa não permaneceria por muito tempo sem a ação enérgica do governo do estado, quando o governador Manoel Ribas em abril de 1936 ordena o fechamento de todos os núcleos integralistas do Paraná, um importante reduto dos seguidores de Plínio Salgado. A partir daí, há então uma intensa mobilização por parte dos integralistas em propagandear a decisão do governador em toda a imprensa integralista do Brasil e denunciá-la como um ato arbitrário, levando mesmo o próprio Plínio Salgado a manifestar várias vezes sua contrariedade com a decisão. Prosseguindo, o autor trata das formas de militar que os integralistas encontraram durante o período de fechamento da AIB, como participação em datas cívicas e homenagens a ilustres brasileiros, todos sem a camisa verde, até o momento da reabertura da AIB em dezembro de 1936 sem maiores explicações por parte do governo do estado (Bertonha, 2013).

O sexto artigo é assinado por Odilon Caldeira Neto e se intitula "O Sigma na rede: a utilização da internet pelos grupos neointegralistas". $\mathrm{O}$ autor abre seu estudo com uma breve introdução sobre a Ação Integralista Brasileira na década 1930, partindo já para a atuação dos integralistas no pós-Segunda Guerra, cristalizada pela fundação por Plínio Salgado do Partido Representação Popular, funcionando até 1965 com a sua extinção pela ditadura civil-militar. A partir daí, a apropriação do integralismo se inicia. Primeiramente com a refundação da Ação Integralista Brasileira em 1980 por Anésio de Lara Campos Júnior, que não obteve unanimidade entre os antigos integralistas, e posteriormente pela fundação de três grupos neointegralistas, a Frente Integralista Brasileira, o Movimento Integralista e Linearista Brasileiro e a Ação Integralista Revolucionária, todos estes já fundados no século XXI, e que travam uma disputa interna para cooptação de novos simpatizantes tendo a internet papel fundamental para a propaganda destes grupos, segundo Caldeira, por ser uma ferramenta de baixo custo e fácil acesso (Bertonha, 2013).

A segunda parte do livro tem como artigo de abertura, o trabalho de Micael Alvino da Silva, "A Conferência do Rio de Janeiro e a retirada dos 'Súditos do Eixo' na parte brasileira da Tríplice fronteira”. Através de depoimentos, o historiador busca reconstruir a memória dos antigos moradores de Foz do Iguaçu que foram retirados de suas casas durante a Segunda Guerra Mundial por conta de sua origem ligada a qualquer um dos países que formavam o Eixo (Alemanha, Itália e Japão), sendo na região a presença de alemães e seus descendentes de maior destaque que a de outros grupos. Pela rememoração das então crianças e adolescentes, Silva retraça o trajeto pessoal das testemunhas, povoado de frustrações por conta da retirada forçada, do cansaço extremo da viagem, da incerteza e da indignação de muitos por se verem como brasileiros que jamais ofereceriam riscos à sua pátria (Bertonha, 2013).

O artigo de Márcio José Pereira, "Autoritarismo e repressão no Paraná durante o Estado Novo: a ação da DOPS/PR contra os inimigos da nação" trata das diferentes formas de controle que o Estado Novo utilizou para conseguir implantar seu projeto de nacionalização das colônias alemãs no Paraná. Este trabalho se utiliza basicamente de fontes de registros policiais e atenta para o fato das pressões dos Estados Unidos serem constantes para que o Brasil se adequasse à sua política contrária aos países que compunham o Eixo na Segunda Guerra Mundial, porém sem deixar de considerar o caráter dúbio da relação de Vargas com a Alemanha, cheia de idas e vindas, tensões e negociações que muitas vezes causavam preocupação dos embaixadores americanos. 
Através de extensa gama de documentos, o autor faz um levantamento de uma série de restrições e proibições que atingiram os chamados "súditos do Eixo" no período do Estado Novo, acentuando o maior rigor durante os anos que se seguiram da declaração de guerra ao Eixo em 1942, ao fim do conflito em 1945, e como aquelas atingiram não somente os alemães, italianos e seus descendentes, mas todas as pessoas de Curitiba, que se viram mobilizadas pelo esforço de guerra (Bertonha, 2013).

O nono artigo do livro, intitulado "Território e nacionalismo na construção da Ordem - a lógica da suspeição no norte do estado do Paraná (1932-1945)” de Rogério Dezem, Amir El Hakim de Paula e Rosângela Kimura reflete sobre questões como a tentativa de controle estatal do povoamento brasileiro, baseado em teorias eugênicas europeias em voga no começo do século XX, em especial o caso da imigração japonesa, considerada perigosa e de difícil assimilação pelo governo durante o Estado Novo, assim como um breve parecer sobre a postura de Oliveira Vianna frente ao caso da vinda de estrangeiros para o Brasil. O estudo por fim foca o estado do Paraná e a política do interventor Manoel Ribas, assim como examina a provável existência de campos de trabalho forçados para imigrantes japoneses no Paraná (Bertonha, 2013).

A terceira e última parte do livro é aberta pelo capítulo "A política teuto-italiana para a Síria e o Líbano e a circularidade local dos fascismos entre as guerras mundiais", de Fábio Bacila Sahd. O artigo é iniciado com uma contextualização da situação política e ideológica de alguns países do Oriente Médio, que se viram imersos em um mundo repleto de teorias sociais e econômicas dos mais variados matizes e que sofreram transformações profundas - no caso mais específico, o fim do Império Otomano - na virada do século, e que não deixaram de ser atingidos pelas ideias e práticas fascistas. Segundo o autor, a decepção das classes médias e da juventude intelectualizada com a atuação de França e Grã-Bretanha na região serviu para aumentar as chances de sucesso dos ideais fascistas. $\mathrm{O}$ artigo propõe uma comparação entre as políticas externas alemã e italiana para o Oriente Médio, com a preponderância desta sobre aquela, principalmente devido à sua ligação histórica com o mar Mediterrâneo, sua tentativa de reviver um grande império italiano, além da busca de uma área de influência fora da Europa e que pudesse enfraquecer as potências Inglaterra e França. Entretanto é reconhecido o fato de que apesar do esforço dos países fascistas, principalmente Itália, a influência das potências liberais jamais chegou a ser ameaçada (Bertonha, 2013).

O último capítulo do livro é de autoria de Shesmman Fernandes Barros de Melo, "Totalitarismo nas histórias em quadrinhos: Superman entre a foice e o martelo". O autor traça um histórico do surgimento das histórias em quadrinhos (HQ), enquanto faz um paralelo com o fato de toda HQ fazer parte mesmo de um universo próprio inserido na sociedade em que foi produzido. Melo traça rapidamente a história desenvolvida na HQ, no qual o Superman nasceria na União Soviética de Stálin e terminaria governando o mundo. Desenvolvendo seu raciocínio, o autor traça aproximações entre a história e o conceito de totalitarismo desenvolvido por ele mesmo e retratado em vários aspectos da HQ(Bertonha, 2013).

A temática do livro é essencial para a compreensão de fenômenos autoritários no Brasil. A obra marca posição em um momento de incertezas ideológicas que pairam sobre a sociedade em geral, mas particularmente na Academia. A compreensão dos movimentos de caráter autoritário é de inegável valor por parte dos autores e a escolha dos artigos pelo organizador foi extremamente acertada. A valorização da historiografia de ponta, que é marca de Bertonha, se faz sentir. O movimento integralista, maior 
desses movimentos, é tratado com atenção em suas diferentes facetas - sejam práticas ou teóricas - numa dinâmica de constante renovação historiográfica tão necessária para o debate bem fundamentado. Os artigos que tratam da AIB regionalmente se enquadram no momento de valorização das experiências locais que é uma das características do trabalho historiográfico hoje. A análise da atuação dos grupos integralistas na internet é extremamente valiosa para entendermos o momento que passa boa parte da humanidade, revelando uma onda neoconservadora cristalizada no destaque que determinadas organizações de extrema-direita vem tendo no cenário internacional. O estudo acerca da situação dos chamados "Súditos do Eixo" é fundamental para entendermos um momento da história brasileira, muitas vezes deixado à margem da historiografia tradicional, e a aproximação de casos fora do Brasil, como a União Soviética, a Síria e o Líbano é pensada de forma correta quando tenta contextualizar o panorama mundial da época e para entender semelhanças e distâncias entre os casos estudados. 